\title{
Gut Microbiota Composition Before and After Use of Proton Pump Inhibitors
}

\author{
Mariko Hojo ${ }^{1}$ (1) - Takashi Asahara ${ }^{2,3} \cdot$ Akihito Nagahara $^{1} \cdot$ Tsutomu Takeda $^{4} \cdot$ Kohei Matsumoto $^{1} \cdot$ Hiroya Ueyama $^{1}$. \\ Kenshi Matsumoto ${ }^{1}$. Daisuke Asaoka ${ }^{4}$ Takuya Takahashi ${ }^{2,3} \cdot$ Koji Nomoto $^{3,5} \cdot$ Yuichiro Yamashiro $^{2}$. \\ Sumio Watanabe ${ }^{1}$
}

Received: 17 February 2018 / Accepted: 10 May 2018 / Published online: 24 May 2018

(c) The Author(s) 2018

\begin{abstract}
Background Recently, problems associated with proton pump inhibitor (PPI) use have begun to surface. PPIs influence the gut microbiota; therefore, PPI use may increase the risk of enteric infections and cause bacterial translocation. In this study, we investigated fecal microbiota composition, fecal organic acid concentrations and $\mathrm{pH}$, and gut bacteria in the blood of the same patients before and after PPI use.

Methods Twenty patients with reflux esophagitis based on endoscopic examination received 8 weeks of treatment with PPIs. To analyze fecal microbiota composition and gut bacteria in blood and organic acid concentrations, 16S and 23S rRNAtargeted quantitative RT-PCR and high-performance liquid chromatography were conducted.

Results Lactobacillus species were significantly increased at both 4 and 8 weeks after PPI treatment compared with bacterial counts before treatment ( $P=0.011$ and $P=0.002$, respectively). Among Lactobacillus spp., counts of the L. gasseri subgroup, L. fermentum, the $L$. reuteri subgroup, and the L. ruminis subgroup were significantly increased at 4 and 8 weeks after treatment compared with counts before treatment. Streptococcus species were also significantly increased at 4 and 8 weeks after PPI treatment compared with counts before treatment $(P<0.01$ and $P<0.001$, respectively). There was no significant difference in the total organic acid concentrations before and after PPI treatment. Detection rates of bacteria in blood before and after PPI treatment were 22 and 28\%, respectively, with no significant differences.

Conclusions Our quantitative RT-PCR results showed that gut dysbiosis was caused by PPI use, corroborating previous results obtained by metagenomic analysis.
\end{abstract}

Keywords Proton pump inhibitor $\cdot$ Bacterial translocation $\cdot$ Microbiota $\cdot$ Lactobacillus $\cdot$ Streptococcus

Mariko Hojo

mhojo@juntendo.ac.jp

1 Department of Gastroenterology, Juntendo University School of Medicine, 2-1-1 Hongo, Bunkyo-ku, Tokyo 113-8421, Japan

2 Probiotics Research Laboratory, Juntendo University Graduate School of Medicine, Tokyo, Japan

3 Yakult Central Institute, Tokyo, Japan

4 Department of Gastroenterology, Juntendo Tokyo Koto Geriatric Medical Center, Tokyo, Japan

5 Division of Molecular Microbiology, Tokyo University of Agriculture, Tokyo, Japan

\section{Introduction}

The prevalence of gastroesophageal reflux disease (GERD) has increased worldwide, most likely due to changes in dietary patterns and increasing obesity [1]. The increasing prevalence of GERD has been associated with decreased prevalence of Helicobacter pylori infection, especially in Japan [2]. Proton pump inhibitors (PPIs) that suppress acid production and result in increased gastric $\mathrm{pH}$ are the most frequently used drugs for treatment of GERD [3]. The prophylactic use of aspirin to prevent coronary heart disease and cerebrovascular disease is commonly recommended [4], and PPIs are used to reduce upper gastrointestinal injuries associated with aspirin [5]. With the global growth of older populations, the prevalence of bone fractures [6] and osteoarthritis is increasing [7]. Nonsteroidal anti-inflammatory 
drugs (NSAIDs) are often used as painkillers to alleviate pain associated with these diseases, and PPIs are also used to prevent NSAID-induced ulcers [8]. Moreover, in clinical trials, the tolerability of PPIs was similar to that of placebo, and PPIs have been concluded to be very safe drugs $[9,10]$. Accordingly, the numbers of prescriptions for PPIs have increased significantly, and the duration of treatment has also increased.

Recently, problems associated with PPI use have begun to surface. Long-term PPI use may affect nutrient absorption including calcium malabsorption and the resulting increased risk of bone fracture [11]. PPI use may increase the risk of enteric infections, such as Clostridium difficile and Campylobacter, as well as community-acquired pneumonia [12-14]. PPI use may also increase the incidence of small intestinal bacterial overgrowth [15]. In addition, PPI use is potentially associated with development of spontaneous bacterial peritonitis in cirrhotic patients with ascites or cryptogenic liver abscess, which might be caused by bacterial translocation $[16,17]$. The gut microbiota plays an important role in host resistance against colonization by exogenous enteric microbes and overgrowth of indigenous commensals [18]. Several observation and intervention studies found that PPIs altered the gut microbiota composition [19-23]. Accordingly, the increased risk of enteric infections in PPI users may be caused by the influence of PPIs on the gut microbiota. Moreover, intestinal bacterial overgrowth promotes bacterial translocation [24]; PPIs are therefore likely to be one of the risk factors for bacterial translocation.

Organic acids have various pathophysiological effects on mucosal blood flow in the gastrointestinal tract [25], intestinal epithelial proliferation [26], intestinal motility [27], and control of the intraluminal $\mathrm{pH}$ [28] and are major energy sources for intestinal epithelial cells [29]. Since organic acids are produced by colonic bacteria, any alteration in gut microbiota composition may be associated with a change in organic acid composition [30].

In this current study, we quantitatively investigated the fecal microbiota composition, fecal organic acid concentrations and $\mathrm{pH}$, and the gut bacteria in the blood in the same patients before and after PPI use.

\section{Methods}

\section{Subjects}

This was an observational study. Study participants were recruited from patients who visited the outpatient clinic of the Department of Gastroenterology, Juntendo University Hospital, between October 2014 and September 2016. All patients were at least 20 years of age and had been shown to have $\geq$ grade A reflux esophagitis according to the Los
Angeles classification [31] by endoscopic examination within 6 months prior to recruitment. Patients who had received PPIs within 1 month, who had taken antibiotics, a living bacterial preparation and/or yogurt within 1 month, who had a past history of gastrointestinal resection, and patients who had upper gastrointestinal ulcer(s) (except ulcer scars) or malignant lesion(s) were excluded from this study. The study protocol was reviewed and approved by the Juntendo University Ethics Committee (No. 13-096). Written informed consent was obtained from all patients. All participants received 8 weeks of treatment with PPIs [esomeprazole $(20 \mathrm{mg})$, rabeprazole $(10 \mathrm{mg})$, or lansoprazole $(30 \mathrm{mg})$ once a day].

\section{Determination of the Bacterial Count by $16 \mathrm{~S}$ and 235 rRNA-Targeted Quantitative Reverse Transcription-PCR (RT-qPCR)}

Fresh fecal samples were obtained from participants before treatment and 4 and 8 weeks after the start of treatment. Fecal samples were placed directly into two tubes (about $1.0 \mathrm{~g} /$ tube) by the participants; one tube contained $2 \mathrm{~mL}$ of RNAlater $^{\circledR}$ (Ambion, Austin, TX) for fecal bacterial analysis, and the other tube was used for fecal organic acid concentration and $\mathrm{pH}$ analysis. Samples were kept at $-20^{\circ} \mathrm{C}$ in a cooler box with refrigerants and sent or brought to Juntendo University by participants. Samples for bacterial analysis were stored in a refrigerator at $4{ }^{\circ} \mathrm{C}$, and samples for organic acid concentration and $\mathrm{pH}$ analysis were kept in a freezer at $-20{ }^{\circ} \mathrm{C}$ in Juntendo University.

Blood samples were obtained from participants before treatment and 8 weeks after the start of treatment. Blood (1 mL) was added to $2 \mathrm{~mL}$ of RNAprotect Bacterial Reagent (Qiagen, Hilden, Germany) immediately after collection and stored at $-80^{\circ} \mathrm{C}$. Both fecal and blood samples were transported at $-20{ }^{\circ} \mathrm{C}$ to Yakult Central Institute (Tokyo, Japan). To quantify the bacteria present in the samples, we extracted total RNA fractions from feces and blood using a modification of the acid guanidinium thiocyanate-phenol-chloroform extraction method [32-35] and examined the gut microbiota composition and plasma levels of gut bacteria using $16 \mathrm{~S}$ and $23 \mathrm{~S}$ rRNA-targeted RT-qPCR using the Yakult Intestinal Flora-SCAN analysis system (YIF-SCAN ${ }^{\circledR}$, Yakult Honsha Co., Ltd., Tokyo, Japan). YIF-SCAN ${ }^{\circledR}$ analysis can quantify the abundance of a targeted bacterial population, including subdominant/dominant populations, with high resolution $[32,33]$. Moreover, the YIF-SCAN ${ }^{\circledR}$ system has been shown to be highly effective for counting blood bacteria [32], and because RNA can be used as an indicator of bacterial cell viability, YIF-SCAN ${ }^{\circledR}$ analysis is capable of detecting viable bacteria $[32,36]$. Three serial dilutions of each extracted RNA sample were used for rRNA-targeted RT-qPCR, and the threshold cycle values in the linear range 
of the assay were applied to the standard curve to obtain the corresponding bacterial cell count for each fecal or blood sample. In the present study, predominant anaerobes present in the human intestine (Clostridium coccoides group, Clostridium leptum subgroup, Bacteroides fragilis group, Bifidobacterium, Atopobium cluster, and Prevotella) and intestinal subdominant populations (Clostridium difficile, Clostridium perfringens, Lactobacillus, Enterobacteriaceae, Enterococcus, Streptococcus, Staphylococcus, and Pseudomonas) were examined. The specificity of the RT-qPCR assay using group-, genus-, and species-specific primers was determined as described previously [32, 33]. Primers used in this study are listed in Table 1 [32-34, 37-39].

\section{Measurement of Fecal Organic Acid Concentrations and pH}

Fecal organic acid concentrations were determined as described previously [35] with slight modification. Briefly, frozen samples were homogenized in fourfold volumes of $0.15 \mathrm{~mol} / \mathrm{L}$ perchloric acid and allowed to stand at $4{ }^{\circ} \mathrm{C}$ for $12 \mathrm{~h}$. The suspension was then centrifuged at 20,400 $\times g$ at $4{ }^{\circ} \mathrm{C}$ for $10 \mathrm{~min}$. The resulting supernatant was passed through a filter with a pore size of $0.45 \mu \mathrm{m}$ (Millipore Japan, Tokyo, Japan). The sample was analyzed for organic acids using a high-performance liquid chromatography system (432 Conductivity Detector; Waters Co., Milford, MA). The fecal $\mathrm{pH}$ was analyzed using an IQ $150 \mathrm{pH} /$ Thermometer (IQ Scientific Instruments, Inc., Carlsbad, CA).

\section{Statistical Analysis}

Statistical analyses were performed using IBM SPSS Statistics Desktop version 22.0 software (IBM Japan Ltd., Tokyo, Japan). Half of the lower limit of detection was substituted as the fecal bacterial count for undetectable values [40, 41]. The Wilcoxon signed-rank test and Fisher's exact probability test were used for data analysis. $P<0.05$ was considered to be statistically significant.

\section{Results}

\section{Baseline Characteristics and Prescribed PPIs}

Twenty patients participated in this study. The characteristics of the patients in this study are summarized in Table 2. The male-to-female ratio was 13:7, the mean age was 60.2 years, and the mean body mass index was $23.9 \mathrm{~kg} / \mathrm{m}^{2}$. Only one patient was $H$. pylori-positive. The predominantly prescribed PPI was esomeprazole.

\section{Fecal Bacteria, Organic Acid Concentrations, and pH}

Fecal samples from all patients were examined. Fecal samples from three time points (before, 4 weeks after, and 8 weeks after the start of PPI treatment) from 19 patients were obtained. Because a fecal sample from one patient 4 weeks after the start of treatment could not be obtained, fecal samples from two time points (before and 8 weeks after the start of treatment) were obtained from this patient.

Total fecal bacteria counts before treatment, 4 weeks after the start of treatment, and 8 weeks after the start of treatment were $10.6 \pm 0.6 \log _{10}$ cells/g feces, $10.5 \pm 0.5 \log _{10}$ cells/g feces, and $10.5 \pm 0.4 \log _{10}$ cells/g feces, respectively (Table 3). Significant differences in total bacterial counts between pre-treatment and post- 4 weeks of treatment and between pre-treatment and post- 8 weeks of treatment were not observed. Similarly, significant differences in bacterial counts for each obligate anaerobe between pre-treatment and post- 4 weeks or post- 8 weeks of treatment were not observed. In contrast, the total counts of Lactobacillus, which are facultative anaerobes, were significantly different between pre-treatment and post- 4 weeks of treatment and between pre-treatment and post- 8 weeks of treatment $(P=0.011$ and $P=0.002$, respectively). Compared with counts before treatment, the bacterial counts increased significantly at 4 and 8 weeks after the start of treatment in the L. gasseri subgroup $(P=0.031$ and $P=0.002$, respectively), $L$. fermentum ( $P=0.002$ and $P=0.002$, respectively), the $L$. reuteri subgroup ( $P=0.001$ and $P=0.001$, respectively), and the $L$. ruminis subgroup $(P=0.022$ and $P=0.011$, respectively). Similarly, the bacterial counts of $L$. brevis after 4 weeks of treatment were significantly increased compared to counts before treatment $(P=0.025)$. Counts of facultative anaerobes in the genus Streptococcus were also significantly increased at both 4 and 8 weeks after the start of treatment compared with counts before treatment $(P=0.005$ and $P<0.0001$, respectively), and counts of facultatively anaerobic members of the family Enterobacteriaceae were significantly increased at 8 weeks after treatment compared with counts before treatment $(P=0.003)$. Counts and detection rates of facultative anaerobes in the genus Staphylococcus were also significantly increased after 8 weeks of treatment compared with those before treatment $(P=0.002)$.

Fecal total organic acid concentrations before treatment, 4 weeks after the start of treatment, and 8 weeks after the start of treatment were $102.8 \pm 33.5,122.9 \pm 44.2$, and $104.1 \pm 44.1 \mu \mathrm{mol} / \mathrm{g}$ feces, respectively (Table 4 ). Significant differences both between pre-treatment and post- 4 weeks of treatment and between pre-treatment and post- 8 weeks of treatment were not observed. Formic acid and butyric acid 
Table $1 \quad 16 \mathrm{~S}$ and 23S rRNA gene-targeted specific primers used in this study

\begin{tabular}{|c|c|c|}
\hline Target bacteria & Primer & Sequence $\left(5^{\prime}-3^{\prime}\right)$ \\
\hline \multirow[t]{2}{*}{ Clostridium coccoides group } & $\mathrm{g}-\mathrm{Ccoc}-\mathrm{F}$ & AAATGACGGTACCTGACTAA \\
\hline & g-Ccoc-R & CTTTGAGTTTCATTCTTGCGAA \\
\hline \multirow[t]{2}{*}{ Clostridium leptum subgroup } & sg-Clept-F & GCACAAGCAGTGGAGT \\
\hline & sg-Clept-R3 & CTTCCTCCGTTTTGTCAA \\
\hline \multirow[t]{2}{*}{ Bacteroides fragilis group } & $\mathrm{g}-\mathrm{Bfra}-\mathrm{F} 2$ & AYAGCCTTTCGAAAGRAAGAT \\
\hline & g-Bfra-R & CCAGTATCAACTGCAATTTTA \\
\hline \multirow[t]{2}{*}{ Bifidobacterium } & g-Bifid-F & CTCCTGGAAACGGGTGG \\
\hline & g-Bifid-R & GGTGTTCTTCCCGATATCTACA \\
\hline \multirow[t]{2}{*}{ Atopobium cluster } & g-Atopo-F & GGGTTGAGAGACCGACC \\
\hline & g-Atopo-R & CGGRGCTTCTTCTGCAGG \\
\hline \multirow[t]{2}{*}{ Prevotella } & g-Prevo-F & CACRGTAAACGATGGATGCC \\
\hline & g-Prevo-R & GGTCGGGTTGCAGACC \\
\hline \multirow[t]{2}{*}{ Clostridium difficile } & Cd-lsu-F & GGGAGCTTCCCATACGGGTTG \\
\hline & Cd-lsu-R & TTGACTGCCTCAATGCTTGGGC \\
\hline \multirow[t]{2}{*}{ Clostridium perfringens } & s-Clper-F & GGGGGTTTCAACACCTCC \\
\hline & CIPER-R & GCAAGGGATGTCAAGTGT \\
\hline \multirow[t]{2}{*}{ Lactobacillus gasseri subgroup } & sg-Lgas-F & GATGCATAGCCGAGTTGAGAGACTGAT \\
\hline & sg-Lgas-R & TAAAGGCCAGTTACTACCTCTATCC \\
\hline \multirow[t]{2}{*}{ Lactobacillus brevis } & s-Lbre-F & ATTTTGTTTGAAAGGTGGCTTCGG \\
\hline & s-Lbre-R & ACССТTGAACAGTTACTCTCAAAGG \\
\hline \multirow[t]{2}{*}{ Lactobacillus casei subgroup } & sg-Lcas-F & ACCGCATGGTTCTTGGC \\
\hline & sg-Lcas-R & CCGACAACAGTTACTCTGCC \\
\hline \multirow[t]{2}{*}{ Lactobacillus fermentum } & LFer-1 & CCTGATTGATTTTGGTCGCCAAC \\
\hline & LFer-2 & ACGTATGAACAGTTACTCTCATACGT \\
\hline \multirow[t]{2}{*}{ Lactobacillus fructivorans } & s-Lfru-F & TGCGCCTAATGATAGTTGA \\
\hline & s-Lfru-R & GATACCGTCGCGACGTGAG \\
\hline \multirow[t]{2}{*}{ Lactobacillus plantarum subgroup } & sg-Lpla-F & CTCTGGTATTGATTGGTGCTTGCAT \\
\hline & sg-Lpla-R & GTTCGCCACTCACTCAAATGTAAA \\
\hline \multirow[t]{2}{*}{ Lactobacillus reuteri subgroup } & sg-Lreu-F & GAACGCAYTGGCCCAA \\
\hline & sg-Lreu-R & TCCATTGTGGCCGATCAGT \\
\hline \multirow[t]{2}{*}{ Lactobacillus ruminis subgroup } & sg-Lrum-F & CACCGAATGCTTGCAYTCACC \\
\hline & sg-Lrum-R & GCCGCGGGTCCATCCAAAA \\
\hline \multirow[t]{2}{*}{ Lactobacillus sakei subgroup } & sg-Lsak-F & CATAAAACCTAMCACCGCATGG \\
\hline & sg-Lsak-R & TCAGTTACTATCAGATACRTTCTTCTC \\
\hline \multirow[t]{2}{*}{ Enterobacteriaceae } & En-lsu-3F & TGCCGTAACTTCGGGAGAAGGCA \\
\hline & En-lsu-3'R & TCAAGGACCAGTGTTCAGTGTC \\
\hline \multirow[t]{2}{*}{ Enterococcus } & g-Encoc-F & ATCAGAGGGGGATAACACTT \\
\hline & g-Encoc-R & АСТCTCATCCTTGTTCTTCTC \\
\hline \multirow[t]{2}{*}{ Streptococcus } & g-Str-F & AGCTTAGAAGCAGCTATTCATTC \\
\hline & g-Str-R & GGATACACCTTTCGGTCTCTC \\
\hline \multirow[t]{2}{*}{ Staphylococcus } & g-Staph-F & TTTGGGCTACACACGTGCTACAATGGACAA \\
\hline & g-Staph-R & AACAACTTTATGGGATTTGCWTGA \\
\hline \multirow[t]{2}{*}{ Pseudomonas } & PSD7F & CAAAACTACTGAGCTAGAGTACG \\
\hline & PSD7R & TAAGATCTCAAGGATCCCAACGGCT \\
\hline
\end{tabular}

Group-, genus-, or species-specific primer sets were developed by using 16S rDNA sequences, except for Cd-lsu-F/R, En-lsu-3F/3'R, and g-Str-F/R, which targeted 23S rDNA concentrations at 4 weeks after treatment were significantly increased compared with concentrations before treatment
$(P=0.022$ and $P=0.033$, respectively $) . \mathrm{pH}$ values were not significantly different among the three measurement points. 
Table 2 Study participant characteristics and prescribed PPIs

\begin{tabular}{ll}
\hline & $\begin{array}{l}\text { Patients } \\
n=20\end{array}$ \\
\hline Sex $(n)$ male:female & $13: 7$ \\
Age (years), mean $\pm \mathrm{SD}$ & $60.2 \pm 12.5$ \\
Body mass index $\left(\mathrm{kg} / \mathrm{m}^{2}\right)$, mean $\pm \mathrm{SD}$ & $23.9 \pm 3.4$ \\
Current smoker $(n)$ & 2 \\
Alcohol intake $(n)$ & \\
Nondrinker & 10 \\
Occasional drinker & 5 \\
Habitual drinker & 5 \\
Helicobacter pylori $(n)$ & \\
Negative & 11 \\
Negative after eradication & 8 \\
Positive & 1 \\
Diseases $(n)$ & \\
Diabetes & \\
Hypertension & 1 \\
Dyslipidemia & 4 \\
Prescribed PPIs $(n)$ & 4 \\
Lansoprazole & \\
Rabeprazole & 2 \\
Esomeprazole & 16 \\
\hline
\end{tabular}

PPIs proton pump inhibitors; $S D$ standard deviation

\section{Detection of Bacteria in Blood}

Blood samples from 18 of the 20 participants were examined. A blood sample from one of the remaining participants could not be obtained, and one blood sample from a participant was not stored properly after collection. The minimum detectable number of bacteria was 1 bacterial cell per $1 \mathrm{~mL}$ of blood. Bacteria were detected in the blood of four of 18 subjects before treatment and in five of 18 subjects after 8 weeks of treatment (Table 5). There was no significant difference in the detection rate of bacteria in the blood before and after PPI treatment. No two blood samples from the same patient contained detectable numbers of bacteria at both time points pre-treatment and post-treatment. Two of the four subjects from whom bacteria were detected in the blood were habitual drinkers. However, bacteria were not detectable in the blood in any of the habitual drinkers after 8 weeks of treatment. Furthermore, bacteria were not detected in the blood of a diabetic patient either before or after treatment. The mean bacterial counts detected before treatment and after 8 weeks of treatment were 5.0 and 8.8 cells $/ \mathrm{mL}$, respectively. The Clostridium leptum subgroup, the Atopobium cluster, the genus Prevotella, and the genus Streptococcus were detected in patients before treatment, and the Atopobium cluster and genus Streptococcus were detected in patients after 8 weeks of PPI treatment.
Streptococcus spp. detected before treatment were $S$. salivarius and $S$. gordonii. The counts of $S$. salivarius were 8 cells $/ \mathrm{mL}$, and the counts of $S$. gordonii were 2 cells $/ \mathrm{mL}$. Streptococcus spp. detected after treatment were $S$. salivarius and S. oralis. S. salivarius was detected in two patients. The counts of $S$. salivarius were $1 \mathrm{cell} / \mathrm{mL}$ in each patient. $S$. oralis was also detected in two patients. The counts of $S$. oralis were 23 and 15 cells/mL (Fig. 1).

\section{Discussion}

The results of the present study showed that significant differences in the numbers of Lactobacillus, which is a subdominant population in the intestine, were observed between pre- and post-PPI treatment, while significant differences in the numbers of each predominant obligate anaerobe in the feces of PPI users between pre- and post-treatment were not observed. Recently, bacterial rRNA gene-based, metagenomic analyses have been conducted to analyze the composition of the human gut microbiome [22, 23, 42, 43]. However, it is difficult to quantify subdominant important intestinal genera using this approach. Therefore, we used the YIF-SCAN $^{\circledR}$ system to perform bacterial analysis. The YIF$\mathrm{SCAN}^{\circledR}$ system can quantify the abundance of the targeted bacterial population, including subdominant populations and dominant populations, with high sensitivity and has the ability to detect viable bacteria [32, 33, 36].

Previous large cohort studies of PPI users and intervention studies of PPI use for 4 weeks reported increases in bacteria from the genus Streptococcus [19, 20, 22, 23]. In the present study, we also observed an increase in the genus Streptococcus. Members of the genus Streptococcus are commensals of the human oral cavity, throat, and nasal cavity. Gastric acidity is known to inactivate ingested microorganisms [44]. Therefore, gastric acid may act as a barrier against bacterial influx down into the lower gastrointestinal tract from upper regions such as the oral cavity. Because PPIs reduce stomach acidity, the barrier function becomes weakened. This may explain the finding of increased Streptococcus counts detected in this study. Our results corroborate the findings of previous studies that employed metagenomic analyses. In addition, for the first time, the current pilot study verified the results of previous studies by using RT-qPCR. No significant differences in blood bacterial detection rates were observed before or after treatment; however, the mean counts of Streptococcus in blood before and after PPI treatment were 5 and 10 cells $/ \mathrm{mL}$, respectively. The Streptococcus $\mathrm{spp}$. detected after PPI treatment were $S$. salivarius and $S$. oralis, which are commensals of the human oral cavity $[45,46]$. This finding shows that bacteria present in the human oral cavity, throat, and nasal cavity increased in the intestine, implying that bacterial translocation may have occurred. Therefore, 
Table 3 Comparisons of fecal bacterial counts before and after PPI treatment

\begin{tabular}{|c|c|c|c|c|c|c|}
\hline \multirow[b]{3}{*}{ Total bacteria } & \multicolumn{6}{|c|}{ Fecal bacterial count (detection rate, $\%$ ) } \\
\hline & \multicolumn{2}{|c|}{ Pre-treatment $(n=20)$} & \multicolumn{2}{|c|}{$\begin{array}{l}\text { Post-4 weeks treatment } \\
(n=19)\end{array}$} & \multicolumn{2}{|c|}{$\begin{array}{l}\text { Post- } 8 \text { weeks treat- } \\
\text { ment }(n=20)\end{array}$} \\
\hline & $10.6 \pm 0.6$ & $(100)$ & $10.5 \pm 0.5$ & $(100)$ & $10.5 \pm 0.4$ & $(100)$ \\
\hline \multicolumn{7}{|l|}{ Obligate anaerobes } \\
\hline Clostridium coccoides group & $10.2 \pm 0.6$ & $(100)$ & $9.8 \pm 0.7$ & $(100)$ & $9.9 \pm 0.6$ & $(100)$ \\
\hline C. leptum subgroup & $9.6 \pm 0.9$ & $(100)$ & $9.6 \pm 0.8$ & $(100)$ & $9.5 \pm 0.9$ & $(100)$ \\
\hline Bacteroides fragilis group & $9.4 \pm 0.7$ & $(100)$ & $9.3 \pm 1.0$ & $(100)$ & $9.5 \pm 0.6$ & $(100)$ \\
\hline Bifidobacterium & $8.6 \pm 1.9$ & $(100)$ & $8.9 \pm 1.3$ & $(100)$ & $8.9 \pm 1.2$ & $(100)$ \\
\hline Atopobium cluster & $9.0 \pm 1.0$ & $(100)$ & $9.1 \pm 0.7$ & $(100)$ & $9.1 \pm 0.8$ & $(100)$ \\
\hline Prevotella & $4.5 \pm 2.6$ & $(45)$ & $4.9 \pm 2.4$ & $(58)$ & $5.4 \pm 2.4$ & $(70)$ \\
\hline C. difficile & $1.9 \pm 1.6$ & $(20)$ & $2.2 \pm 1.7$ & $(32)$ & $1.8 \pm 1.4$ & $(20)$ \\
\hline C. perfringens & $2.5 \pm 2.0$ & $(35)$ & $3.7 \pm 2.5$ & $(58)$ & $3.2 \pm 2.6$ & $(45)$ \\
\hline \multicolumn{7}{|l|}{ Facultative anaerobes } \\
\hline Total Lactobacillus & $5.7 \pm 1.5$ & $(95)$ & $6.8 \pm 1.3^{*}$ & $(100)$ & $7.0 \pm 1.0 * *$ & $(100)$ \\
\hline L. gasseri subgroup & $4.3 \pm 2.0$ & $(75)$ & $5.3 \pm 2.1 *$ & $(89)$ & $5.6 \pm 1.5^{* *}$ & $(75)$ \\
\hline L. brevis & $1.7 \pm 1.4$ & (15) & $2.4 \pm 1.7 *$ & $(42)$ & $2.4 \pm 1.6$ & $(55)$ \\
\hline L. casei subgroup & $3.0 \pm 1.8$ & $(45)$ & $2.9 \pm 1.5$ & (53) & $3.5 \pm 1.5$ & (70) \\
\hline L. fermentum & $3.3 \pm 1.9$ & $(35)$ & $5.2 \pm 2.2 * *$ & $(74 *)$ & $4.8 \pm 2.3 * *$ & $(65)$ \\
\hline L. fructivorans & $1.3 \pm 0.5$ & (5) & $1.3 \pm 0.5$ & $(5)$ & $1.2 \pm 0.4$ & (6) \\
\hline L. plantarum subgroup & $4.1 \pm 1.8$ & $(80)$ & $3.8 \pm 1.3$ & $(90)$ & $4.2 \pm 1.5$ & $(90)$ \\
\hline L. reuteri subgroup & $3.6 \pm 1.7$ & $(70)$ & $5.0 \pm 1.8^{* *}$ & (89) & $4.8 \pm 1.7 * *$ & $(85)$ \\
\hline L. ruminis subgroup & $3.1 \pm 2.5$ & $(40)$ & $4.4 \pm 2.9^{*}$ & $(68)$ & $4.4 \pm 2.7^{*}$ & $(70)$ \\
\hline L. sakei subgroup & $2.8 \pm 1.4$ & $(60)$ & $3.5 \pm 2.0$ & (74) & $3.7 \pm 2.0$ & $(70)$ \\
\hline Enterobacteriaceae & $5.9 \pm 2.1$ & $(85)$ & $6.7 \pm 1.0$ & $(100)$ & $6.9 \pm 1.6^{* *}$ & $(95)$ \\
\hline Enterococcus & $5.3 \pm 1.7$ & $(90)$ & $6.0 \pm 2.3$ & $(84)$ & $5.7 \pm 2.5$ & $(80)$ \\
\hline Streptococcus & $8.7 \pm 0.7$ & $(100)$ & $9.5 \pm 0.8^{* *}$ & $(100)$ & $9.6 \pm 0.7 * * *$ & $(100)$ \\
\hline Staphylococcus & $3.0 \pm 1.5$ & $(55)$ & $3.7 \pm 1.6$ & (74) & $4.5 \pm 1.0 * *$ & $(95 * *)$ \\
\hline \multicolumn{7}{|l|}{ Aerobes } \\
\hline Pseudomonas & $2.2 \pm 1.4$ & (25) & $1.9 \pm 1.0$ & (21) & $2.2 \pm 1.3$ & (30) \\
\hline
\end{tabular}

Values are the mean \pm standard deviation $(\log 10$ cells/g feces $)$

$* P<0.05$ versus Week 0 , pre-PPI treatment

$* * P<0.01$ versus Week 0 , pre-PPI treatment

$* * * P<0.001$ versus Week 0 , pre-PPI treatment
PPI use may be associated with bacterial translocation. PPI use may also increase the risk of sepsis [47-49], as well as enteric infections. Four patients had bacteria in the blood before treatment. Although chronic alcohol consumption or diabetes is associated with bacterial translocation [50], neither alcohol nor diabetes was significantly associated with the presence of bacteria in the blood. The reason for bacteremia before treatment is not currently clear. Further, because the method used for counting bacteria in this study is highly sensitive, a very small amount of bacteria in the blood due to unknown cause might be detected. The results of the present study show that PPI use may cause an increase in indigenous lactobacilli because patients who had received drugs and/or dietary items that affect the gut microbiota, such as antibiotics, living bacterial preparations, or yogurt, were excluded from the present study. Among lactobacilli, counts of the
L. gasseri subgroup, L. fermentum, the L. reuteri subgroup, and the $L$. ruminis subgroup were significantly increased after PPI treatment. It is generally considered that these bacteria have probiotic influences on human health [51-54]. However, there are several case reports demonstrating that lactobacilli caused serious infections such as bacteremia and liver abscesses in susceptible immunocompromised patients $[55,56]$. In addition to our results, increased numbers of Lactobacillus were also observed in patients with diseases such as diabetes mellitus type 2 [36] and Parkinson's disease [57]. The biological effects of probiotics are strain specific [58], and whether these bacteria have probiotic features is determined by a coevolutionary relationship between the bacteria and their hosts [59]. Therefore, it is not clear at present whether increased numbers of such bacteria that are associated with PPI treatment provide harmful or beneficial 
Table 4 Fecal organic acid concentrations and $\mathrm{pH}$
Table 5 Bacterial counts in blood samples

\begin{tabular}{lcccccc}
\hline \multicolumn{7}{c}{ Fecal organic acid concentrations (detection rate, \%) } \\
\cline { 2 - 6 } & Pre-treatment $(n=20)$ & $\begin{array}{l}\text { Post-4 weeks treatment } \\
(n=19)\end{array}$ & \multicolumn{2}{l}{$\begin{array}{l}\text { Post-8 weeks treat- } \\
\text { ment }(n=20)\end{array}$} \\
\hline Total organic acids & $102.8 \pm 33.5$ & $(100)$ & $122.9 \pm 44.2$ & $(100)$ & $104.1 \pm 44.1$ & $(100)$ \\
Succinic acid & $5.2 \pm 9.0$ & $(80)$ & $5.1 \pm 8.5$ & $(68)$ & $2.6 \pm 5.2$ & $(75)$ \\
Lactic acid & $1.3 \pm 1.0$ & $(15)$ & $1.7 \pm 1.3$ & $(21)$ & $2.7 \pm 2.4$ & $(40)$ \\
Formic acid & $0.6 \pm 0.5$ & $(75)$ & $1.5 \pm 1.2^{*}$ & $(79)$ & $1.3 \pm 1.4$ & $(90)$ \\
Acetic acid & $64.4 \pm 20.7$ & $(100)$ & $74.6 \pm 27.9$ & $(100)$ & $62.4 \pm 24.9$ & $(100)$ \\
Propionic acid & $19.2 \pm 6.5$ & $(100)$ & $24.0 \pm 10.6$ & $(100)$ & $21.2 \pm 9.8$ & $(100)$ \\
Butyric acid & $12.5 \pm 7.2$ & $(90)$ & $16.3 \pm 10.3 *$ & $(100)$ & $14.3 \pm 10.0$ & $(95)$ \\
Isovaleric acid & $2.7 \pm 2.0$ & $(60)$ & $2.4 \pm 1.9$ & $(68)$ & $3.0 \pm 1.8$ & $(60)$ \\
Valeric acid & $2.7 \pm 3.4$ & $(55)$ & $2.4 \pm 1.8$ & $(58)$ & $1.8 \pm 1.1$ & $(55)$ \\
pH & $6.6 \pm 0.4$ & $(100)$ & $6.4 \pm 0.6$ & $(100)$ & $6.7 \pm 0.7$ & $(100)$ \\
\hline
\end{tabular}

Values are the mean \pm standard deviation ( $\mu \mathrm{mol} / \mathrm{g}$ feces)

$* P<0.05$ versus Week 0 , pre-PPI treatment

$* * P<0.01$ versus Week 0 , pre-PPI treatment

\begin{tabular}{|c|c|c|}
\hline & $\begin{array}{l}\text { Pre-treatment }(n=18) \\
\text { Median }(\min -\max )(\text { cells } / \mathrm{mL}) \\
n \text {; detection rate }\end{array}$ & $\begin{array}{l}\text { Post- } 8 \text { weeks treatment }(n=18) \\
\text { Median }(\min -\max )(\text { cells } / \mathrm{mL}) \\
n \text {; detection rate }\end{array}$ \\
\hline Total bacteria & $5.0(1-15) ; 4 ; 22 \%$ & $8.8(1-23) ; 5 ; 28 \%$ \\
\hline \multicolumn{3}{|l|}{ Obligate anaerobes } \\
\hline Clostridium coccoides group & $\mathrm{ND}$ & ND \\
\hline C. leptum subgroup & $4(2-6) ; 2 ; 11 \%$ & ND \\
\hline Bacteroides fragilis group & $\mathrm{ND}$ & $\mathrm{ND}$ \\
\hline Bifidobacterium & $\mathrm{ND}$ & ND \\
\hline Atopobium cluster & $1 ; 1 ; 5.6 \%$ & $4 ; 1 ; 5.6 \%$ \\
\hline Prevotella & $1 ; 1 ; 5.6 \%$ & ND \\
\hline C. difficile & $\mathrm{ND}$ & $\mathrm{ND}$ \\
\hline C. perfringens & $\mathrm{ND}$ & $\mathrm{ND}$ \\
\hline \multicolumn{3}{|l|}{ Facultative anaerobes } \\
\hline Total Lactobacillus & $\mathrm{ND}$ & $\mathrm{ND}$ \\
\hline L. gasseri subgroup & $\mathrm{ND}$ & ND \\
\hline L. brevis & $\mathrm{ND}$ & $\mathrm{ND}$ \\
\hline L. casei subgroup & $\mathrm{ND}$ & $\mathrm{ND}$ \\
\hline L. fermentum & ND & ND \\
\hline L. fructivorans & ND & $\mathrm{ND}$ \\
\hline L. plantarum subgroup & $\mathrm{ND}$ & $\mathrm{ND}$ \\
\hline L. reuteri subgroup & $\mathrm{ND}$ & ND \\
\hline L. ruminis subgroup & $\mathrm{ND}$ & $\mathrm{ND}$ \\
\hline L. sakei subgroup & $\mathrm{ND}$ & ND \\
\hline Enterobacteriaceae & $\mathrm{ND}$ & $\mathrm{ND}$ \\
\hline Enterococcus & ND & $\mathrm{ND}$ \\
\hline Streptococcus & $5(2-8) ; 2 ; 11 \%$ & $10(1-23) ; 4 ; 22 \%$ \\
\hline Staphylococcus & ND & $\mathrm{ND}$ \\
\hline \multicolumn{3}{|l|}{ Aerobes } \\
\hline Pseudomonas & $\mathrm{ND}$ & ND \\
\hline
\end{tabular}

$N D$ not detected 


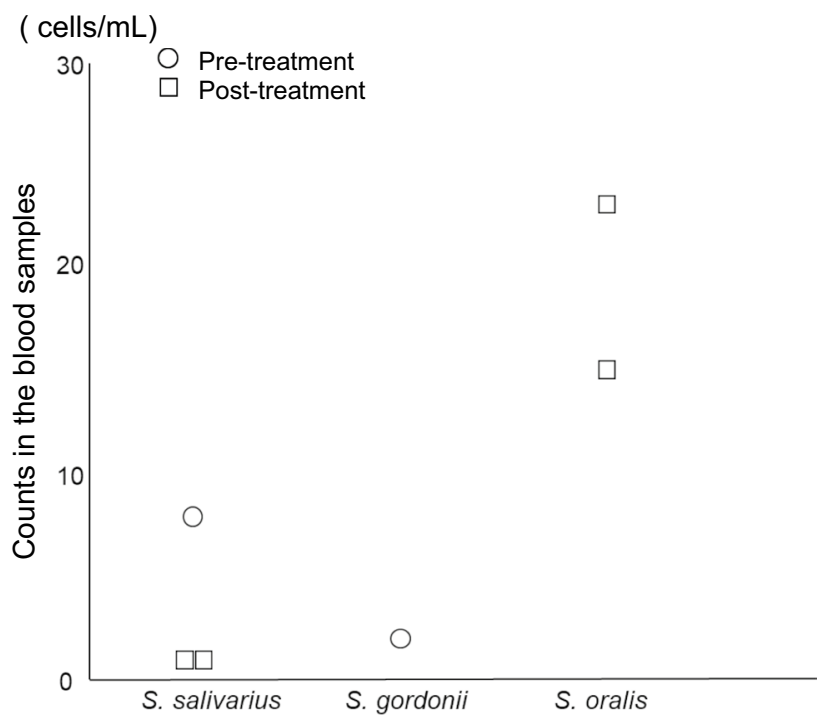

Fig. 1 Counts of each species of Streptococcus detected in blood samples before and after PPI treatment. PPI, proton pump inhibitor; $S$, Streptococcus

influences on human health. However, if bacterial translocation was caused by PPI use, then PPI use would have a negative influence on human health.

With regard to total and individual organic acid concentrations and $\mathrm{pH}$ values, there were no significant differences between values at pre-treatment and post- 8 weeks of PPI treatment. Although formic acid and butyric acid concentrations were significantly increased after 4 weeks of treatment compared with concentrations before treatment, significant differences disappeared after 8 weeks of treatment. PPI treatment therefore did not cause long-lasting changes in fecal organic acid concentrations. The reasons underlying the increases in formic acid and butyric acid concentrations after 4 weeks of treatment are currently not clear.

Regarding the limitations of this study, major drawbacks include the small sample size and short treatment period. Twenty patients and 8 weeks of treatment may be insufficient to evaluate the effects of PPI treatment. Moreover, because we used the proprietary YIF-SCAN ${ }^{\circledR}$ system, which may have biased results, studies using alternative approaches are needed.

In conclusion, our results by RT-qPCR demonstrate that gut dysbiosis was caused by PPI use, corroborating results obtained by previous metagenomic analyses. Further largescale studies on longer-term PPI use, substantial effects of PPI use on human health caused by gut dysbiosis, and whether PPI use causes bacterial translocation to blood are needed.

Acknowledgments We wish to express our sincere gratitude to Norikatsu Yuki, Akira Takahashi, and Yukiko Kado (Yakult Central
Institute) for their valuable assistance in performing the microbiota analyses.

\section{Compliance with ethical standards}

Conflict of interest The authors declare that they have no conflict of interest.

Open Access This article is distributed under the terms of the Creative Commons Attribution-NonCommercial 4.0 International License (http://creativecommons.org/licenses/by-nc/4.0/), which permits any noncommercial use, distribution, and reproduction in any medium, provided you give appropriate credit to the original author(s) and the source, provide a link to the Creative Commons license, and indicate if changes were made.

\section{References}

1. Savarino E, Zentilin P, Marabotto E, et al. Overweight is a risk factor for both erosive and non-erosive reflux disease. Dig Liver Dis. 2011;43:940-945.

2. Nakajima S, Nishiyama Y, Yamaoka M, Yasuoka T, Cho E. Changes in the prevalence of Helicobacter pylori infection and gastrointestinal diseases in the past 17 years. J Gastroenterol Hepatol. 2010;25(Suppl 1):S99-S110.

3. Robinson M. Review article: the pharmacodynamics and pharmacokinetics of proton pump inhibitors-overview and clinical implications. Aliment Pharmacol Ther. 2004;20(Suppl 6):1-10.

4. Wolff T, Miller T, Ko S. Aspirin for the primary prevention of cardiovascular events: an update of the evidence for the U.S. Preventive Services Task Force. Ann Intern Med. 2009;150:405-410.

5. Mo C, Sun G, Lu ML, et al. Proton pump inhibitors in prevention of low-dose aspirin-associated upper gastrointestinal injuries. World J Gastroenterol. 2015;21:5382-5392.

6. Fife D, Barancik JI. Northeastern Ohio Trauma Study III: incidence of fractures. Ann Emerg Med. 1985;14:244-248.

7. Hassett G, Hart DJ, Manek NJ, Doyle DV, Spector TD. Risk factors for progression of lumbar spine disc degeneration: the Chingford Study. Arthritis Rheum. 2003;48:3112-3117.

8. Singh G, Triadafilopoulos G. Appropriate choice of proton pump inhibitor therapy in the prevention and management of NSAID-related gastrointestinal damage. Int J Clin Pract. 2005;59:1210-1217.

9. Wilde MI, McTavish D. Omeprazole. An update of its pharmacology and therapeutic use in acid-related disorders. Drugs. 1994;48:91-132.

10. Carswell CI, Goa KL. Rabeprazole: an update of its use in acidrelated disorders. Drugs. 2001;61:2327-2356.

11. Insogna KL. The effect of proton pump-inhibiting drugs on mineral metabolism. Am J Gastroenterol. 2009;104(Suppl 2):S2-S4.

12. Leonard J, Marshall JK, Moayyedi P. Systematic review of the risk of enteric infection in patients taking acid suppression Am J Gastroenterol.. 2007;102:2047-2056. (quiz 2057).

13. Naito Y, Kashiwagi K, Takagi T, Andoh A, Inoue R. Intestinal dysbiosis secondary to proton-pump inhibitor use. Digestion. 2018;97:195-204.

14. Freedberg DE, Lebwohl B, Abrams JA. The impact of proton pump inhibitors on the human gastrointestinal microbiome. Clin Lab Med. 2014;34:771-785. 
15. Lombardo L, Foti M, Ruggia O, Chiecchio A. Increased incidence of small intestinal bacterial overgrowth during proton pump inhibitor therapy. Clin Gastroenterol Hepatol. 2010;8:504-508.

16. de Vos M, De Vroey B, Garcia BG, et al. Role of proton pump inhibitors in the occurrence and the prognosis of spontaneous bacterial peritonitis in cirrhotic patients with ascites. Liver Int. 2013;33:1316-1323.

17. Wang YP, Liu CJ, Chen TJ, Lin YT, Fung CP. Proton pump inhibitor use significantly increases the risk of cryptogenic liver abscess: a population-based study. Aliment Pharmacol Ther. 2015;41:1175-1181.

18. Kamada N, Chen GY, Inohara N, Nunez G. Control of pathogens and pathobionts by the gut microbiota. Nat Immunol. 2013;14:685-690.

19. Jackson MA, Goodrich JK, Maxan ME, et al. Proton pump inhibitors alter the composition of the gut microbiota. Gut. 2016;65:749-756.

20. Imhann F, Bonder MJ, Vich Vila A, et al. Proton pump inhibitors affect the gut microbiome. Gut. 2016;65:740-748.

21. Takagi T, Naito Y, Inoue R, et al. The influence of long-term use of proton pump inhibitors on the gut microbiota: an age-sex-matched case-control study. J Clin Biochem Nutr. 2018;62:100-105.

22. Otsuka T, Sugimoto M, Inoue R, et al. Influence of potassiumcompetitive acid blocker on the gut microbiome of Helicobacter pylori-negative healthy individuals. Gut. 2017;66:1723-1725.

23. Freedberg DE, Toussaint NC, Chen SP, et al. Proton pump inhibitors alter specific taxa in the human gastrointestinal microbiome: a crossover trial. Gastroenterology. 2015;149:e889.

24. Berg RD. Bacterial translocation from the gastrointestinal tract. Adv Exp Med Biol. 1999;473:11-30.

25. Mortensen FV, Nielsen H, Mulvany MJ, Hessov I. Short chain fatty acids dilate isolated human colonic resistance arteries. Gut. 1990;31:1391-1394.

26. Scheppach W, Bartram P, Richter A, et al. Effect of short-chain fatty acids on the human colonic mucosa in vitro. JPEN J Parenter Enteral Nutr. 1992;16:43-48.

27. Kamath PS, Hoepfner MT, Phillips SF. Short-chain fatty acids stimulate motility of the canine ileum. Am J Physiol. 1987;253:G427-G433.

28. Umesaki Y, Yajima T, Yokokura T, Mutai M. Effect of organic acid absorption on bicarbonate transport in rat colon. Pflugers Arch. 1979;379:43-47.

29. Chapman MA. The role of the colonic flora in maintaining a healthy large bowel mucosa. $n n$ R Coll Surg Engl. 2001;83:75-80.

30. Tana C, Umesaki Y, Imaoka A, Handa T, Kanazawa M, Fukudo $\mathrm{S}$. Altered profiles of intestinal microbiota and organic acids may be the origin of symptoms in irritable bowel syndrome. Neurogastroenterol Motil. 2010;22:e114-e515.

31. Lundell LR, Dent J, Bennett JR, et al. Endoscopic assessment of oesophagitis: clinical and functional correlates and further validation of the Los Angeles classification. Gut. 1999;45:172-180.

32. Matsuda K, Tsuji H, Asahara T, Kado Y, Nomoto K. Sensitive quantitative detection of commensal bacteria by rRNAtargeted reverse transcription-PCR. Appl Environ Microbiol. 2007;73:32-39.

33. Matsuda K, Tsuji H, Asahara T, Matsumoto K, Takada T, Nomoto K. Establishment of an analytical system for the human fecal microbiota, based on reverse transcription-quantitative PCR targeting of multicopy rRNA molecules. Appl Environ Microbiol. 2009;75:1961-1969.

34. Sakaguchi S, Saito M, Tsuji H, et al. Bacterial rRNA-targeted reverse transcription-PCR used to identify pathogens responsible for fever with neutropenia. J Clin Microbiol. 2010;48:1624-1628.

35. Ohigashi S, Sudo K, Kobayashi D, et al. Changes of the intestinal microbiota, short chain fatty acids, and fecal $\mathrm{pH}$ in patients with colorectal cancer. Dig Dis Sci. 2013;58:1717-1726.
36. Sato J, Kanazawa A, Ikeda F, et al. Gut dysbiosis and detection of "live gut bacteria" in blood of Japanese patients with type 2 diabetes. Diabetes Care. 2014;37:2343-2350.

37. Matsuda K, Tsuji H, Asahara T, et al. Sensitive quantification of Clostridium difficile cells by reverse transcription-quantitative PCR targeting rRNA molecules. Appl Environ Microbiol. 2012;78:5111-5118.

38. Matsuki T, Watanabe K, Fujimoto J, et al. Development of $16 \mathrm{~S}$ rRNA-gene-targeted group-specific primers for the detection and identification of predominant bacteria in human feces. Appl Environ Microbiol. 2002;68:5445-5451.

39. Matsuki T, Watanabe K, Fujimoto J, Takada T, Tanaka R. Use of 16S rRNA gene-targeted group-specific primers for real-time PCR analysis of predominant bacteria in human feces. Appl Environ Microbiol. 2004;70:7220-7228.

40. Suzuki Y, Ikeda K, Sakuma K, et al. Association between Yogurt Consumption and Intestinal Microbiota in Healthy Young Adults Differs by Host Gender. Front Microbiol. 2017;8:847.

41. Morita C, Tsuji H, Hata T, et al. Gut dysbiosis in patients with anorexia nervosa. PLoS ONE. 2015;10:e0145274.

42. Turnbaugh PJ, Hamady M, Yatsunenko T, et al. A core gut microbiome in obese and lean twins. Nature. 2009;457:480-484.

43. Qin J, Li Y, Cai Z, et al. A metagenome-wide association study of gut microbiota in type 2 diabetes. Nature. 2012;490:55-60.

44. Howden CW, Hunt RH. Relationship between gastric secretion and infection. Gut. 1987;28:96-107.

45. Kaci G, Goudercourt D, Dennin V, et al. Anti-inflammatory properties of Streptococcus salivarius, a commensal bacterium of the oral cavity and digestive tract. Appl Environ Microbiol. 2014;80:928-934.

46. Do T, Jolley KA, Maiden MC, et al. Population structure of Streptococcus oralis. Microbiology (Read Engl). 2009;155:2593-2602.

47. Xu HB, Wang HD, $\mathrm{Li} \mathrm{CH}$, et al. Proton pump inhibitor use and risk of spontaneous bacterial peritonitis in cirrhotic patients: a systematic review and meta-analysis. Genet Mol Res.. 2015;14:7490-7501.

48. Zhou SJ, Wang SQ, Ma YY, et al. Association of proton pump inhibitors with the occurrence of gut-derived bacteraemia in patients with haematological malignancy after chemotherapy. Hematology (Amst Neth). 2016;21:332-337.

49. Ramamoorthy SL, Lee JK, Mintz Y, et al. The impact of protonpump inhibitors on intraperitoneal sepsis: a word of caution for transgastric NOTES procedures. Surg Endosc. 2010;24:16-20.

50. Engen PA, Green SJ, Voigt RM, Forsyth CB, Keshavarzian A. The gastrointestinal microbiome: alcohol effects on the composition of intestinal microbiota. Alcohol Res. 2015;37:223-236.

51. Selle K, Klaenhammer TR. Genomic and phenotypic evidence for probiotic influences of Lactobacillus gasseri on human health. FEMS Microbiol Rev. 2013;37:915-935.

52. Varma P, Dinesh KR, Menon KK, Biswas R. Lactobacillus fermentum isolated from human colonic mucosal biopsy inhibits the growth and adhesion of enteric and foodborne pathogens. J Food Sci. 2010;75:M546-M551.

53. Thomas CM, Hong T, van Pijkeren JP, et al. Histamine derived from probiotic Lactobacillus reuteri suppresses TNF via modulation of PKA and ERK signaling. PloS one. 2012;7:e31951.

54. Taweechotipatr M, Iyer C, Spinler JK, Versalovic J, Tumwasorn S. Lactobacillus saerimneri and Lactobacillus ruminis: novel human-derived probiotic strains with immunomodulatory activities. FEMS Microbiol Lett. 2009;293:65-72.

55. Sherid M, Samo S, Sulaiman S, Husein H, Sifuentes H, Sridhar S. Liver abscess and bacteremia caused by Lactobacillus: role of probiotics? Case report and review of the literature. BMC Gastroenterol. 2016;16:138. 
56. Pararajasingam A, Uwagwu J. Lactobacillus: the not so friendly bacteria. BMJ Case Rep. 2017. https://doi.org/10.1136/bcr-2016218423.

57. Hasegawa $\mathrm{S}$, Goto $\mathrm{S}$, Tsuji $\mathrm{H}$, et al. Intestinal dysbiosis and lowered serum lipopolysaccharide-binding protein in Parkinson's disease. PloS one. 2015;10:e0142164.

58. Fijan S. Microorganisms with claimed probiotic properties: an overview of recent literature. Int J Environ Res Public Health. 2014;11:4745-4767.
59. Papizadeh M, Rohani M, Nahrevanian H, Javadi A, Pourshafie MR. Probiotic characters of Bifidobacterium and Lactobacillus are a result of the ongoing gene acquisition and genome minimization evolutionary trends. Microb. Pathog. 2017;111:118-131. 